\title{
SIGNIFICANT OTHERS AND SOCIAL ALCOHOL USE IN ADOLESCENTS
}

\author{
Galya D. Chamova, \\ Georgi M. Sarov ${ }^{1}$
}

\author{
Department of Social Medicine and \\ Healthcare Management, \\ ${ }^{1}$ Department of Pathophysiology \\ Medical Faculty \\ Trakia University \\ Stara Zagora \\ Bulgaria
}

\begin{abstract}
Summary
The association between adolescent drinking and drinking of significant others is well known but underlying mechanisms are still not well understood. The purpose of the study was to investigate the association between social drinking in adolescents and drinking patterns of their significant others. We conducted a survey using a selfcompleted questionnaire on alcohol drinking habits. Of 903 students (aged 15-19), 279 (30.9\%) were found to be abstainers (NDA) and $455(50.39 \%)$ - social drinkers (SDA). These two groups were compared statistically about drinking patterns of their significant others. It was found that SDA were more likely to have fathers $(\mathrm{OR}=0.26 ; 95 \% \mathrm{CI}=0.19-0.37)$, mothers $\quad(\mathrm{OR}=0.26$; $95 \% \mathrm{CI}=0.19-0.37)$, friends $\quad(\mathrm{OR}=0.26 ; 95 \% \mathrm{CI}=0.19$ $0.37)$ and lovers $(\mathrm{OR}=0.26 ; 95 \% \mathrm{CI}=0.19-0.37)$ that drank socially than NDA, but there were no significant differences in regular drinking of their fathers, friends and lovers. Only SDA mothers were more likely to drink regularly $(\mathrm{OR}=0.26 ; 95 \% \mathrm{CI}=0.19-0.37)$. $\mathrm{SDA}$ were also more likely to receive alcohol offers from all their significant others, except from lovers. Social drinking in adolescence seems to be strongly socially motivated by drinking modeling and social pressure. The SDA mothers' regular drinking is hard to explain in terms of social learning and social control theory and needs an alternative explanation.
\end{abstract}

Key words: parental behavior, significant others, behavioral modeling

\section{Introduction}

Adolescence is a time characterized by the onset and escalation of alcohol use [1] in association with drinking of significant others - parents [2-4] and peers [5], and peer context grows increasingly influential, as adolescents mature [6]. Two major theories examine differently development of alcohol use in adolescence: social learning theory [7-10] and social control theory $[10,11]$. The social learning theory emphasizes exposure to alcohol-using role models and posits that adolescent alcohol use is a learned behavior acquired through social interactions [10]. The social control theory focuses

Received: October 30, 2015 
on the constraining function of social bonds. The social bond may be weakened when parents do not exercise supervision on their adolescents $[12$,$] and there is much research supporting the$ relation between adolescent alcohol use and parenting style [5, 13-15]. Peer influence is considered to be the other social factor predisposing alcohol consumption among adolescents [16-18] in the form of modeling (i.e., adolescents adapt their drinking behavior to the drinking behavior of peers) and persuasion (i.e., adolescents are being encouraged or persuaded to adapt their alcohol consumption) [19] and close friends affect most initiation and persistence of alcohol use [18]. Many studies have found high similarities in drinking behavior in peer groups [20-22] that are often interpreted as the outcome of peer influence processes.

In a previous study of ours [23] we found that regular drinking in adolescence was influenced by significant others much more indirectly, through a „regular drinking” behavioral pattern than through direct offers of alcohol and social pressure. Now we examine if this is true for social drinking.

\section{Methods}

\section{Conception and measurements}

As we studied drinking models (habits), we did not ask respondents to give details on the quantity and type of alcohol consumed by them and their significant others. Rather, they were asked to focus on the drinking pattern. In view of this, we categorized three drinking patterns: no drinking (abstainers); casual drinking (social drinking only in special and rare occasions) and regular drinking (no need of special occasions to drink). Respondents were asked to indicate which pattern corresponded to the drinking behavior of their fathers, mothers, friends and lovers, as well to their own drinking behavior. As indicators of social pressure, we used questions about drinking offers coming from parents and peers of the respondents as well as about attitudes to drunkenness expressed by them.

\section{Study design}

All $9^{\text {th }}$ to $12^{\text {th }}$ grade students (15-19 aged) attending three secondary schools of Stara Zagora, Bulgaria were invited to participate in the survey. The study protocol was approved by the Ethics Committee for Clinical Research of the Medical Faculty, Trakia University, Stara
Zagora, Bulgaria and the Regional Inspectorate of the Ministry of Education of Bulgaria. To increase the response rate, the survey was conducted in class hours in cooperation with school authorities. Students were placed in a large room situated at a sufficient distance from each other to provide independent and anonymous answers to the questions. To provide maximum reliability of the data, the questionnaires were collected in a sealed box and each student was free to refuse participation.

\section{Participants}

A total of 1077 students were invited, and 1051 accepted to participate in the study. Of the 1051 participants, 903 filled out the questionnaire correctly and were included in the survey (response rate 83.8\%). Among respondents, 455 students $(50.39 \%)$ identified themselves as social (occasional) drinkers (SDA) and 279 (30.9\%) as abstainers (NDA).

\section{Data analysis}

The two groups - abstainers and social drinkers, were compared statistically for drinking patterns of their significant others, drinking offers coming from parents and peers as well as attitudes to drunkenness expressed by them. Statistical analysis was performed with the SPSS statistical package. Descriptive statistics, Chi-square test and logistic regression were used.

\section{Results}

Drinking patterns of significant others are shown on Table 1. SDAs were more likely to have socially drinking fathers, mothers, friends and beloved persons and not more likely to have significant others with other drinking models. Only one exception from this rule was found SDAs were more likely to have regular drinking mothers without episodes of drunkenness.

As one can see on Table 2, SDAs were more likely to receive drinking offers from all the significant others except from lovers.

Although SDAs were less likely to be intolerant to drunkenness than NDAs, no significant differences were found in their significant others' attitudes to drunkenness (Table $3)$. 
Table 1. Significant differences in drinking patterns of significant others of SADs and NDAs

\begin{tabular}{|c|c|c|c|c|c|}
\hline & $\begin{array}{c}\text { SDA } \\
(n=455) \\
\% \pm \text { SE }\end{array}$ & $\begin{array}{c}\text { NDA }(n=279) \\
\% \pm \text { SE }\end{array}$ & $\mathrm{p}<$ & OR & $95 \% \mathrm{CI}$ \\
\hline \multicolumn{6}{|c|}{ Social drinking } \\
\hline father & $41.76 \pm 2.31$ & $21.51 \pm 2.46$ & 0.001 & 2.62 & $1.86-3.68$ \\
\hline mother & $44.18 \pm 2.33$ & $18.64 \pm 2.33$ & 0.001 & 3.45 & $2.43-4.92$ \\
\hline lover & $38.11 \pm 2.39$ & $9.36 \pm 1.90$ & 0.001 & 5.96 & $3.68-9.65$ \\
\hline friends & $59.78 \pm 2.30$ & $29.03 \pm 2.72$ & 0.001 & 3.63 & $2.64-5.00$ \\
\hline \multicolumn{6}{|c|}{ Regular drinking } \\
\hline father & $37.80 \pm 2.27$ & $35.13 \pm 2.86$ & NS & 1.12 & $0.82-1.53$ \\
\hline mother & $12.97 \pm 1.57$ & $5.73 \pm 1.39$ & 0.010 & 2.45 & $1.38-4.35$ \\
\hline lover & $9.95 \pm 1.47$ & $8.09 \pm 1.78$ & NS & 1.26 & $0.71-2.22$ \\
\hline friends & $23.96 \pm 2.00$ & $23.30 \pm 2.53$ & NS & 1.04 & $0.73-1.47$ \\
\hline \multicolumn{6}{|c|}{ 1.1. Regular drinking without episodes of drunkenness } \\
\hline father & $31.21 \pm 2.17$ & $26.16 \pm 2.63$ & NS & 1.28 & $0.92-1.79$ \\
\hline mother & $12.75 \pm 1.56$ & $4.66 \pm 1.26$ & 0.001 & 2.99 & $1.61-5.56$ \\
\hline lover & $7.77 \pm 1.32$ & $5.11 \pm 1.44$ & NS & 1.56 & $0.79-3.10$ \\
\hline friends & $15.16 \pm 1.68$ & $12.54 \pm 1.98$ & NS & 1.25 & $0.80-1.93$ \\
\hline \multicolumn{6}{|c|}{ 1.2. Regular drinking with episodes of drunkenness } \\
\hline father & $6.59 \pm 1.16$ & $8.96 \pm 1.71$ & NS & 0.72 & $0.41-1.25$ \\
\hline mother & $0.22 \pm 0.22$ & $1.08 \pm 0.62$ & NS & 0.20 & $0.02-1.96$ \\
\hline lover & $2.18 \pm 0.72$ & $2.98 \pm 1.11$ & NS & 0.73 & $0.27-1.98$ \\
\hline friends & $11.87 \pm 1.52$ & $12.90 \pm 2.01$ & NS & 0.91 & $0.58-1.43$ \\
\hline
\end{tabular}

Table 2. Significant differences in drinking offers coming from significant others of SDAs and NDAs

\begin{tabular}{lccccc}
\hline & $\begin{array}{c}\text { SDA } \\
(\mathrm{n}=455) \\
\% \pm \mathrm{SE}\end{array}$ & $\begin{array}{c}\mathrm{NDA}(\mathrm{n}=279) \\
\% \pm \mathrm{SE}\end{array}$ & $\mathrm{p}<$ & OR & $95 \% \mathrm{CI}$ \\
\hline father & $20.00 \pm 1.88$ & $9.32 \pm 1.74$ & 0.001 & 2.43 & $1.53-3.87$ \\
mother & $8.57 \pm 1.31$ & $3.58 \pm 1.11$ & 0.010 & 2.52 & $1.24-5.14$ \\
lover & $15.05 \pm 1.76$ & $10.21 \pm 1.98$ & $\mathrm{NS}$ & 1.56 & $0.94-2.57$ \\
friends & $43.96 \pm 2.33$ & $34.41 \pm 2.84$ & 0.050 & 1.50 & $1.10-2.04$ \\
classmates & $32.09 \pm 2.19$ & $24.01 \pm 2.56$ & 0.050 & 1.50 & $1.07-2.10$ \\
\hline
\end{tabular}

Table 3. Significant differences in attitudes to drunkenness of SDAs and NDAs and their significant others

\begin{tabular}{lccccc}
\hline & $\begin{array}{c}\text { SDA } \\
(\mathrm{n}=455) \\
\% \pm \mathrm{SE}\end{array}$ & $\begin{array}{c}\mathrm{NDA}(\mathrm{n}=279) \\
\% \pm \mathrm{SE}\end{array}$ & $\mathrm{p}<$ & OR & $95 \% \mathrm{CI}$ \\
\hline $\begin{array}{l}\text { The drunks are very unpleasant for: } \\
\text { respondent }\end{array}$ & $38.68 \pm 2.28$ & $51.97 \pm 2.99$ & 0.001 & 0.58 & $0.43-0.79$ \\
respondent's father & $21.76 \pm 1.93$ & $23.30 \pm 2.53$ & $\mathrm{NS}$ & 0.92 & $0.64-1.31$ \\
respondent's mother & $42.42 \pm 2.32$ & $38.71 \pm 2.92$ & $\mathrm{NS}$ & 1.17 & $0.86-1.58$ \\
respondent's lover & $18.20 \pm 1.90$ & $13.19 \pm 2.21$ & $\mathrm{NS}$ & 1.46 & $0.93-2.30$ \\
respondent's friends & $14.73 \pm 1.66$ & $15.41 \pm 2.16$ & $\mathrm{NS}$ & 0.95 & $0.63-1.44$ \\
respondent's classmates & $7.47 \pm 1.23$ & $5.02 \pm 1.31$ & $\mathrm{NS}$ & 1.53 & $0.81-2.90$ \\
\hline
\end{tabular}




\section{Discussion}

Our findings support the opinion that adolescent drinking associates with significant others' drinking $[2-5,13-18,20-22]$. The fact that adolescents and their significant others share same drinking patterns supports the social learning theory [7-10]. SDAs also reported social pressure for drinking in the form of alcohol offers, but we found no data about restrictive pressure, preventing heavy drinking models. But social learning and social control combine in different forms in different pools of significant others.

According to our data, parents are the important factor in social drinking in adolescence as they introduce drinking models and actively stimulate social drinking by drinking offers. Obviously, SDAs were more likely to have parents that assess social drinking as something generally good. We also confirm that mothers' drinking associates with social drninking in adolescents as others report [24], but we cannot explain these findings on the base of our study.

We have also confirmed that peers are an important factor for drinking in adolescence [5, 20-22] as social modeling and social control were both possible explanations of friends' but not for lovers'influence. As the social-cognitive model predicts, lovers' drinking patterns in our study were closest to SDA drinking patterns than to the rest of significant others. SDA were six times more likely to have socially drinking lovers, while only 3.5 times more likely to have socially drinking friends and mothers and 2.6 times more likely to have socially drinking fathers. On the other hand, SDAs were not more likely to receive lovers' drinking offers, and were more likely to receive such offers from parents and friends. This data is in contradiction with the social control theory. Therefore, social modeling is the most probable explanation for lovers' influence on social drinking in adolescence. We can speculate that couples share same social drinking patterns, probably because of simultaneous attendance in some situations that provoke drinking (parties), yet drinking is not important for the quality of intimate bonds and there is no social pressure in this direction.

Another direction of discussion comes from the fact that SDAs were more likely to be tolerant to drunkenness than NDAs, although no difference in such tolerance among their significant others was found. Although social drinking does not present real danger for health, decreased intolerance to drunkenness is a disturbing predictor of possible future drinking problems. Obviously, SDAs do not differentiate well different types of drinking and under such a massive social drinking stimulation tend to perceive drinking as generally good without enough criticism about its heavy forms.

\section{Conclusions}

Our data suggest that both social learning and social control are possible factors for social alcohol drinking in adolescence but in different combination for fathers, mothers, friends and lovers. Social drinking seems to be perceived as something generally good and socially acceptible, but socially drinking adolescents tend to generalize this attitude to all forms of drinking that may predispose them to future drinking problems. Preventive work with parents should emphasise such a danger.

\section{Acknowledgements}

This study was supported by an institutional research grant at Medical Faculty, Trakia University, Stara Zagora, Bulgaria (grant number 26/2014).

\section{Refferences}

1. Duncan SC, Duncan TE, Strycker LA. Alcohol use from ages 9-16: A cohort-sequential latent growth model. Drug Alcohol Depend. 2006; 81(1):71-81.

2. Eitle D. The moderating effects of peer substance use on the family structure-adolescent substance use association: Quantity versus quality of parenting. Addict Behav. 2005;30(5):963-80.

3. Latendresse SJ, Rose RJ, Viken RJ, Pulkkinen L, Kaprio J, Dick DM. Parenting mechanisms in links between parents' and adolescents' alcohol use behaviors. Alcohol Clin Exp Res. 2008 Feb;32(2):322-30.

4. Pettersson C, Lindén-Boström M, Eriksson C. Parental attitudes and behavior concerning youth alcohol consumption: do sociodemographic factors matter? Scand J Public Health. 2009;37(5): 509-17.

5. Chassin L, Hussong A, Barrera MJr, Molina BSG, Trim R, Ritter J. Adolescent substance use. In: Lerner RM, Steinberg L, editors. Handbook of adolescent Psychology. 2nd ed. Hoboken, NJ: John Wiley \& Sons, Inc; 2004. p. 665-696. 
6. Brow BB. Adolescents' relationships with peers. In: Lerner RM, Steinberg L, editors. Handbook of adolescent Psychology. 2nd ed. Hoboken, NJ: John Wiley \& Sons, Inc; 2004. p. 363-394.

7. Akers RL, Krohn MD, Lanza-Kaduce L, Radosevich M. Social learning and deviant behavior: A specific test of a general theory. Am Sociol Rev. 1979;44(4): 636-55.

8. Bandura A. Social learning theory. Englewood Cliffs, NJ: Prentice-Hall; 1977.

9. Bandura A. Social foundations of thought and action: a social cognitive theory. Englewood Cliffs, NJ: Prentice-Hall; 1986.

10. Petraitis J, Flay BR, Miller TQ. Reviewing theories of adolescent substance use: Organizing pieces in the puzzle. Psychol Bull. 1995;11791):67-86.

11. Hirschi T. Causes of delinquency. Berkeley, CA: University of California Press; 1969.

12. Hops H, Duncan TE, Duncan SC, Stoolmiller M. Parent substance use as a predictor of adolescent use: a six-year lagged analysis. Ann Behav Med. 1996;18(3):157-64.

13. Barnes GM, Reifman AS, Farrell MP, Dintcheff BA. The effects of parenting on the development of adolescent alcohol misuse: A six-wave latent growth model. J Marriage Fam. 2000;6291):17586.

14. Jackson C, Henriksen L, Dickinson D. Alcoholspecific socialization, parenting behaviors, and alcohol use by children. J Stud Alcohol. 1999;60(3):362-7.

15. Jones DJ, Forehand R, Brody G, Armistead L. Parental monitoring in African American, single mother-headed families. Behav Modif. 2003;27(4):435-57.
16. Schulenberg J, Maggs JL, Dielman TE, Leech SL, Kloska DD, Laetz VB. On peer influences to get drunk: A panel study of young adolescents. Merrill-Palmer Quarterly 1999;45(1):108-42.

17. Swadi $H$. Individual risk factors for adolescent substance use. Drug Alcohol Depend. 1999;55(3):209-24.

18. Urberg KA, Deg irmenciog $`$ lu SM, Pilgrim C. Close friend and group influence on adolescent cigarette smoking and alcohol use. Dev Psychol. 1997;33(5):834-44.

19. Graham JW, Marks G, Hansen WB. Social influence processes affecting adolescent substance use. J Appl Psychol. 1991;76(2):291-8.

20. Bogenschneider K, Wu MY, Rafaelli M, Tsay JC. Parent influences on adolescent orientation and substance use: the interface of parenting practices and values. Child Dev. 1998;69(6):1672-88.

21. Engels RCME, Knibbe RA, De Vries H, Drop MJ, Van Breukelen GJP. Influences of parental and best friends' smoking and drinking on adolescent use: a longitudinal study. J Appl Soc Psychol. 1999;29(2):337-61.

22. Prinstein MJ, Boergers J, Spirito A. Adolescents' and their friends' health-risk behavior: Factors that alter or add to peer influence. J Pediatr Psychol. 2001;26(5):287-98.

23. Chamova GD, Sarov GM. Direct and indirect impacts of significant others for regular alcohol use in adolescents. Trakia J Sci. 2014;12(Suppl 1):430-2.

24. White HR. Parental modeling and parenting behavior effects on offspring alcohol and cigarette use. A growth curve analysis. J Subst Abuse. 2000;12(3):287-310. 